\title{
AVALIAÇÃO FUNCIONAL DO JOELHO EM PRATICANTES DE MUSCULAÇÃ̃O
}

Rosana Fátima de Almeida

Altair Argentino Pereira Júnior

\section{Resumo}

O joelho tem como função suportar grandes forças, oferecer estabilidade e grande amplitude de movimento. A mobilidade é fornecida pela estrutura óssea, e a estabilidade é fornecida pelos tecidos moles, ligamentos, músculos e cartilagens. A articulação do joelho está envolvida em diferentes lesões músculo esquelética, acometendo adultos jovens e atletas. Porém a atividade física é de extrema importância para a promoção da saúde e bem estar dos indivíduos. O objetivo deste estudo foi verificar o nível funcional do joelho em indivíduos praticantes de musculação. Foram avaliados 48 indivíduos com faixa etária de 16 a 50 anos. A escala de Lysholm foi utilizada para coleta de dados. Os resultados obtidos, pelo escore da escala de Lysholm e pela avaliação subjetiva, evidenciaram que a maior parte dos pesquisados apresentou níveis funcionais categorizados como muito bom e bom para a articulação do joelho. Os participantes apresentaram uma integridade funcional do joelho, sendo assim, a prática da musculação se mostrou benéfica para a articulação do joelho.

\section{Palavras-Chave}

Atividade física; Função do joelho; Musculação.

\section{KNEE FUNCTIONAL EVALUATION IN WEIGHT LIFTERS}

Rosana Fátima de Almeida

Altair Argentino Pereira Júnior

\begin{abstract}
The knee has as its functions to support great forces offering stability and a great range of motion. The mobility is furnished primarily by bone structure and the stability is supplied by the soft tissues, ligaments, muscles and cartilages. The joint of the knee is involved in different lesions muscle skeletal, attacking young adults and athletes. Although physical activity is of extreme importance in promoting good health and well being the individuals. The objective of this study was to verify the knee's function level in weight lifters. Forty eight individuals were studied in age range to 16 and 50 years. It was used the Lysholm scale. The results obtained, by the scale score as well as the subjective evaluation, showed that most of researches have classified the knees function as very well or well. The participants had a functional integrity of the knee, so the practice of weight lifters was beneficial to the knee joint
\end{abstract}

\section{Key-Words}

Physical activity; Knee function; Weight lifters. 


\section{INTRODUÇÃO}

Há pouca estabilidade intrínseca no joelho porque a articulação está localizada nas extremidades de dois braços de alavanca longos a tíbia e o fêmur. Porém a articulação depende muito de estruturas musculares e ligamentares para sua estabilização, sendo assim uma região bastante susceptível a lesões articulares (SCHULZ, 2002).

Segundo Servi (2002) a dor na articulação patelofemoral é uma das queixas mais comuns em todas as idades. Porém, Macnicol (2002) afirma que este distúrbio afeta indivíduos jovens. McConnell (2002) relata que 25 por cento da população irão sofrer com sintomas patelofemorais em algum momento da vida.

Na população em geral a Dor Anterior no Joelho (DAJ) afeta mais mulheres do que homens, em uma proporção de 2:1 (SERVI, 2002). Baker (2002), relata que esta condição musculoesquelética dolorosa afeta principalmente adolescentes e jovens fisicamente ativos. Entre os atletas a prevalência da DAJ será maior no sexo masculino (MALANKA; LEE, 2003). Dugan (2005) relata que a DAJ afetam em maior porcentagem as mulheres atletas do que homens atletas quando estes executam a mesma atividade física (AF) e o mesmo nível de competição.

Atualmente os indivíduos tem sido estimulados a praticar AF considerando os benefícios da $\mathrm{AF}$ na promoção da saúde. Isto parece ser um dos fatores que podem contribuir para o desencadeamento da DAJ, quando a AF não é executada de forma adequada, ou por falta de preparo dos praticantes ou ainda pelo excesso de treinamento (PEREIRA JÚNIOR; LIMA, 2007).

Por outro lado o sedentarismo pode gerar disfunções músculo-esqueléticas, e desequilíbrio entre as forças musculares exercidas na articulação do joelho, gerando desalinhamento articular e hiperpressão patelar. Um mau alinhamento atribuído a forças de pressão aplicadas pelo quadríceps e tendão patelar, gera uma distribuição anormal da força de pressão na articulação patelofemoral, o que, por conseguinte gera dor e degeneração articular (ELIAS et al., 2004).

Alguns estudos têm mostrado a aplicação das escalas de avaliação funcional para determinar a incapacidade dos indivíduos com lesão do joelho (RAMOS NETO, 2000; PEREIRA JÚNIOR; LIMA, 2008). Porém não se encontrou estudos que apresentassem o uso das escalas em indivíduos praticantes de musculação, ou que comparasse a função do joelho nesta população. É necessário investigar o nível Conexões: revista da Faculdade de Educação Física da UNICAMP, Campinas, v. 8, n. 2, p. 83 -92, maio/ago. 2010. 
funcional dos joelhos dos indivíduos, bem como as atividades de vida diária executada por estes a fim de estabelecer relação com as patologias de joelho, o que poderá promover a elaboração de condutas preventivas, e auxiliares no tratamento dos diferentes tipos de acometimentos na articulação do joelho.

Sendo assim, o objetivo deste estudo foi verificar o nível funcional do joelho em indivíduos praticantes de musculação.

\section{METODOLOGIA}

Foi realizado um estudo de caráter descritivo que segundo GIL (1994), tem como objetivo primordial à descrição das características de determinada população ou fenômeno ou o estabelecimento de relações entre variáveis.

A população da pesquisa foi composta por indivíduos praticantes de musculação. A amostra abrangida pelo estudo foi de caráter não probabilístico, do tipo intencional composta por 48 indivíduos com idade compreendida entre 16 e 50 anos, 18 homens (37,5\%) $(\mathrm{x}=25,15 \pm 10,52$ anos) e 30 mulheres $(61,5 \%)$ $(31,83 \pm 14,00$ anos). Os critérios de inclusão da pesquisa: prática de musculação para membros inferiores no mínimo de três meses consecutivos, realizada ao menos uma vez na semana, não possuir histórico de lesões meniscais, ligamentares ou neurológicas, assinar termo de consentimento livre e esclarecido.

Utilizou-se como instrumentos da pesquisa, ficha de avaliação compostas por questões relacionadas aos dados que se pretendeu coletar: atividade profissional, sexo, idade, escolaridade, frequiência semanal e tempo em meses que executa musculação.

Questionário de Lysholm (TEGNER; LYSHOLM, 1985; RAMOS NETO, 2000) para avaliar a função do joelho dos participantes da pesquisa, trata-se de um questionário já validado de domínio público. Cada indivíduo recebeu um questionário que contém itens relacionados a sintomas e limitações funcionais que utiliza uma escala de avaliação de 100 pontos, distribuída da seguinte forma: claudicação (5 pontos), necessidade de suporte ( 5 pontos), bloqueio ou aperto (15 pontos), falseamento ou instabilidade do joelho (25 pontos), dor (25 pontos), edema (10 pontos), subir escadas (10 pontos), agachamento (5 pontos). O questionário solicita que o entrevistado dê uma nota de 0 a 100 para o seu joelho, sendo 100 o melhor.

Os dados obtidos foram tabulados na planilha Excel, e categorizados de acordo com os instrumentos 
usados para coleta de dados, e apresentados na forma de gráficos e tabelas usando a estatística descritiva.

\section{RESULTADOS}

O tempo de prática de musculação para os homens foi de 17,11 $\pm 27,00$ meses, com freqüência semanal de 4,05 \pm 0,99 dias. Para as mulheres foi de 40,36 \pm 70,52 meses, com freqüência semanal de 3,83 $\pm 0,98$ dias na semana.

Com a aplicação da escala de Lysholm foram verificados o nível funcional do joelho em praticantes de musculação, através do escore da escala (Figura 1). E a avaliação subjetiva com notas de 0 a 100 dos joelhos direito e esquerdo que foram relatadas pelos participantes (Figura 2 e 3 ).

Entre os homens, através dos resultados obtidos com o escore da escala de Lysholm, pode-se verificar que $72 \%$ apresentaram pontuação entre (100-90) o que caracterizou como muito bom, $22 \%$ entre (89-80) categorizando como bom, nenhum dos homens participantes obteve pontuação para se encaixar na categoria satisfatório da escala, e 6\% entre (69-0) insatisfatório.

Os resultados encontrados pelo escore da escala nas mulheres participantes da pesquisa foram os seguintes: $80 \%$ obtiveram pontuação entre (100-90) caracterizando como muito bom $7 \%$ entre (89-80) bom, 10\% entre (79-70) satisfatório, e 3\% entre (69-0) insatisfatório.

Também foram analisados através do escore da escala os resultados para o total dos participantes, revelando que $77 \%$ das pessoas obtiveram pontuação entre (100-90) caracterizando como muito bom, $13 \%$ entre (89-80) bom, 6\% entre (79-70) satisfatório, e 4\% entre (69-0) insatisfatório. 


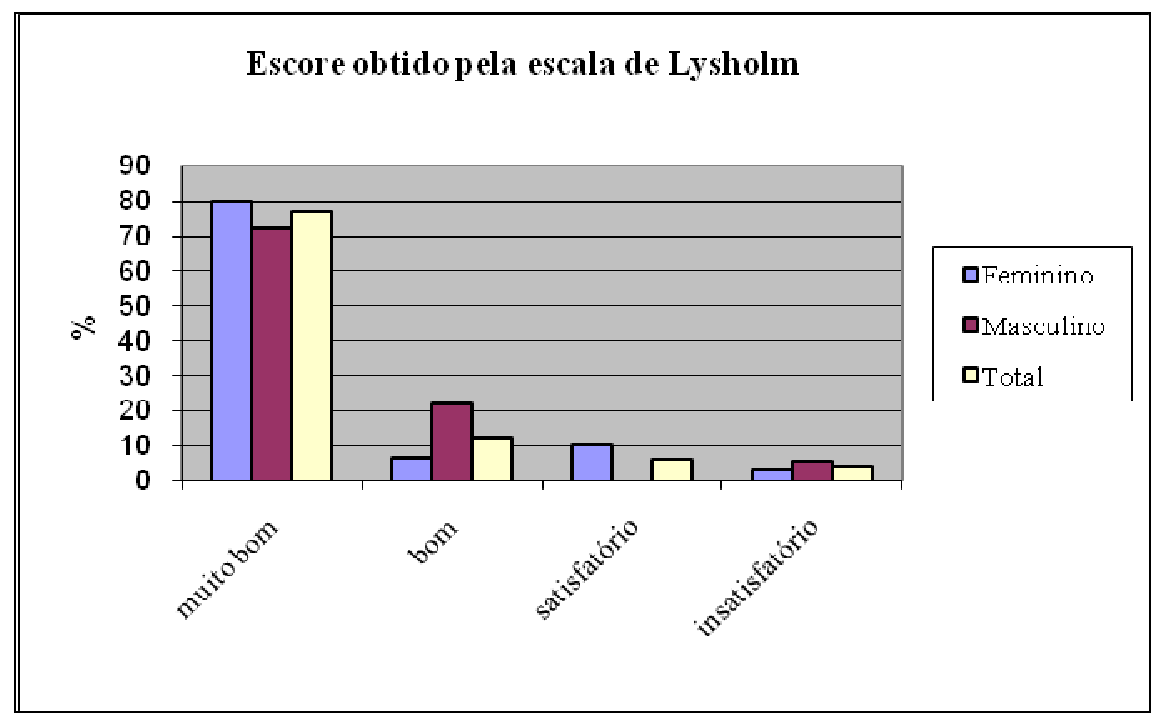

Figura 1 - Escore obtido pela escala de lysholm.

$\mathrm{Na}$ avaliação subjetiva foi solicitado que o participante avaliasse seus joelhos tanto o direito como o esquerdo com notas de (0-100). Com relação ao joelho direito entre os homens os resultados revelaram que $61 \%$ pontuaram seu joelho direito com notas entre (100-90) caracterizando muito bom, 6\% entre (8990) bom, $17 \%$ entre (79-70) satisfatório, e 17\% entre (69-0) insatisfatório. Com relação ao joelho esquerdo os homens classificaram da seguinte forma: 61\% obtiveram pontuação entre (100-90) classificando como muito bom, $11 \%$ entre (89-80) bom, 17\% entre (79-70) satisfatório, e 11\% entre (690) insatisfatório.

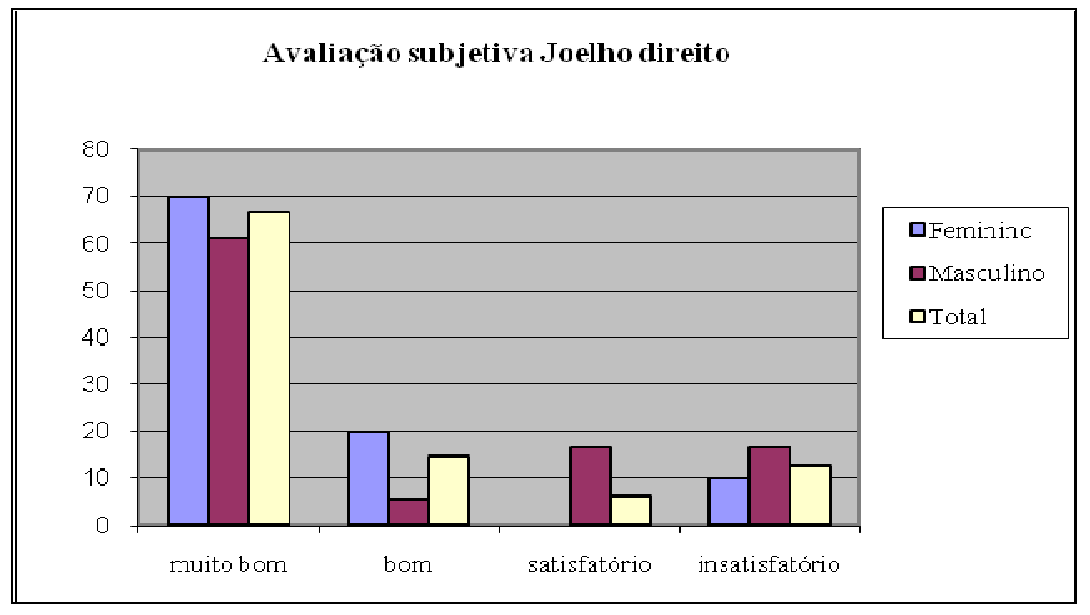

Figura 2 - Avaliação subjetiva do Joelho direito.

Os resultados encontrados nas mulheres em relação ao joelho direito foram o seguinte: $70 \%$ pontuaram 
seu joelho direito entre (100-90) classificando como muito bom, 20\% entre (89-80) bom, nenhuma das mulheres obtiveram pontuação para se encaixar na categoria satisfatório, e 10\% entre (69-0) insatisfatório. Em relação ao joelho esquerdo as mulheres pontuaram da seguinte forma: 80\% pontuaram seu joelho E entre (100-90) classificando como muito bom, 10\% entre (89-80) bom, 3\% entre (79-70) satisfatório, e 7\% entre (69-0) insatisfatório.

Na população em geral os resultados revelaram que $67 \%$ da população pesquisada pontuaram seu joelho direito entre (100-90) muito bom, 15\% entre (89-80) bom, 6\% entre (79-70) satisfatório, e 12\% entre (690) insatisfatório. Já em relação ao joelho esquerdo revelou-se que: $71 \%$ da população pesquisada pontuaram seu joelho E entre (100-90) muito bom, 10\% entre (89-80) bom, 8\% entre (79-70) satisfatório, e $10 \%$ entre (69-0) insatisfatório.

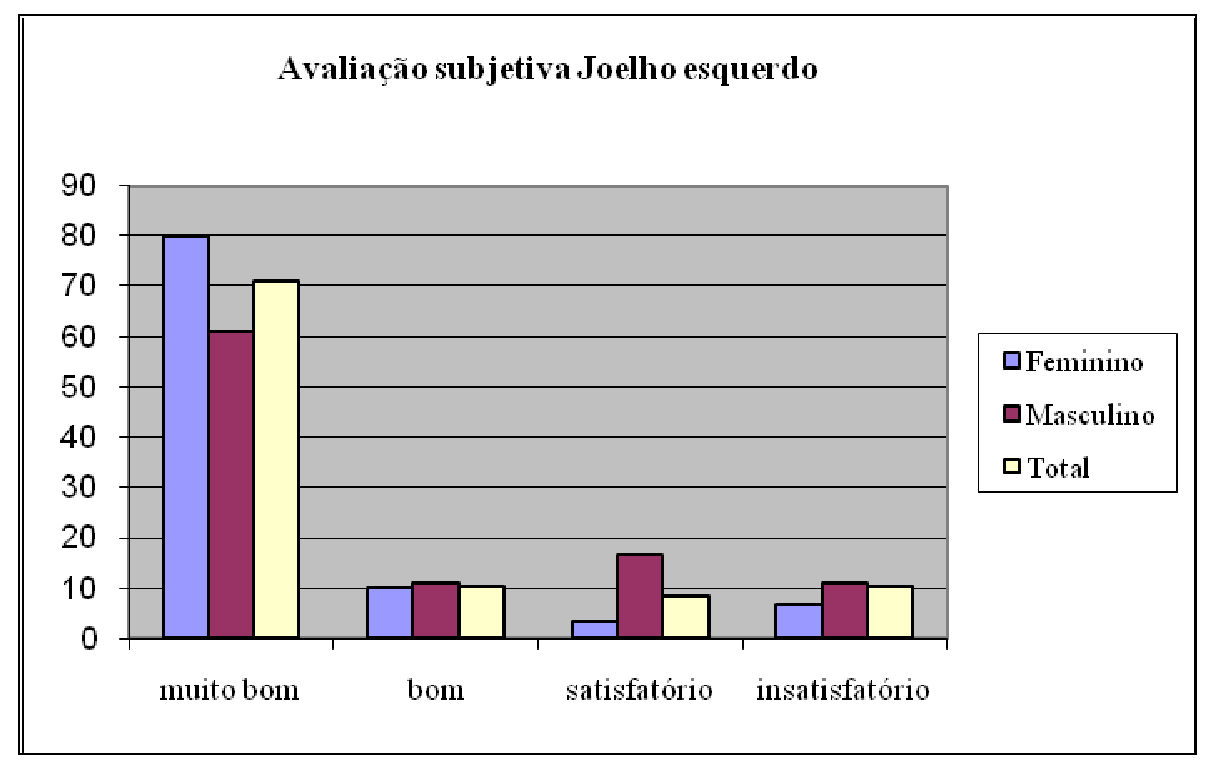

Figura 3 - Avaliação subjetiva do Joelho esquerdo.

Os resultados do IMC apresentados pelos homens nos mostram que nenhum participante se encaixou na categoria magro, $55 \%$ se caracterizaram como normal, $33 \%$ sobrepeso, e $11 \%$ obeso.

Já para as mulheres os resultados apontam que 3\% se caracterizam como magro, 67\% normal, 27\% sobrepeso, e $3 \%$ obeso. Na população em geral pesquisada o índice de massa corporal aponta que $2 \%$ das pessoas se enquadram na classificação de magro, 62\% normal, 29\% sobrepeso, e 6\% obeso (Figura 4). 


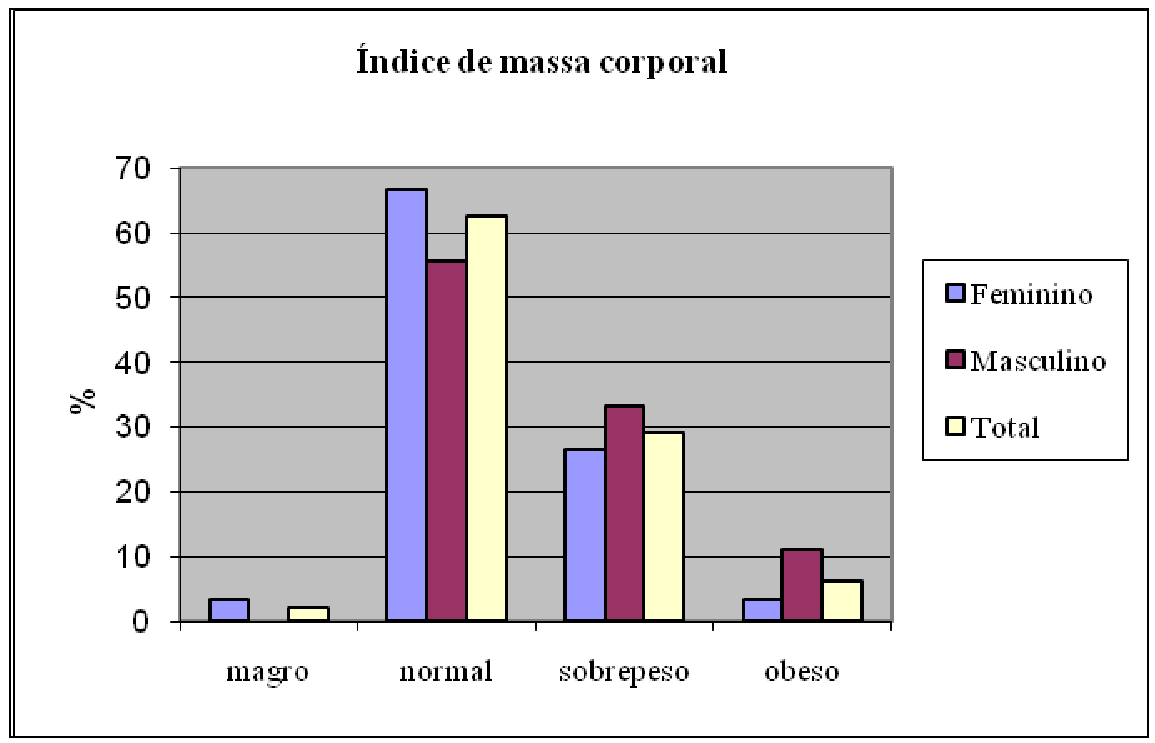

Figura 4 - Índice de massa corporal.

\section{DISCUSSÃO}

Observa-se no presente estudo, que através do escore obtido pela aplicação da Escala de Lysholm, foram obtidos resultados positivos dos participantes da pesquisa, onde a maior parte dos participantes foram categorizados, quanto a função do joelho, em muito bom (77\%) e bom (13\%), condição esta relacionada, principalmente, a ausência da dor no joelho e a limitação que esta ocasiona na execução das atividades de vida diária, ou no exercício, quando este é executado de forma errada (ELIAS et al., 2004).

Um número mínimo de participantes relatou que a condição dos seus joelhos era satisfatória ou insatisfatória, condição esta, que indica a execução correta dos treinos realizados na musculação, e reforça que a prática regular e sistematizada do treinamento resistido tem sido utilizada para a melhoria de importantes componentes da aptidão física em diferentes populações, ocasionando adaptações neuromusculares, como a melhoria da força, resistência e potência muscular (KRAEMER; RATAMESS, 2004).

Em relação a avaliação subjetiva a pesquisa novamente aponta para um resultado positivo, observando a população em geral verificou-se que $67 \%$ da população pesquisada caracterizaram seu joelho direito como muito bom, e $15 \%$ bom. Já em relação ao joelho esquerdo observou-se que $71 \%$ da população pesquisada classificaram seu joelho esquerdo como muito bom e $10 \%$ bom, apontando a satisfação dos participantes da pesquisa em relação à funcionalidade de seu joelho tanto direito como esquerdo. A avaliação subjetiva indica maior satisfação do joelho esquerdo em relação ao joelho direito, isso pode se 
explicar também pela instabilidade das forças exercidas nos exercícios da musculação, pois certas pessoas possuem maior força no membro inferior direito, sendo que na hora do exercício o individuo não consegue dividir as forças igualmente para ambos os joelhos, ocasionando um esforço maior em um dos membros inferiores (DELGADO et al., 2004).

De modo geral os participantes da pesquisa davam-se notas inferiores às notas obtidas pelo preenchimento da escala de Lysholm. Isto pode indicar um cuidado maior que as pessoas têm quanto trata da auto-avaliação, o que se confirma por estudos de Ramos Neto, 2000; Pereira Júnior e Lima, 2008.

Com os resultados do IMC dos participantes observou-se que 2\% participantes foram categorizados como magro e $62 \%$ se caracterizaram como normal. Sendo que esta condição encontrada de peso corporal na faixa ideal é umas das condições que previne o aparecimento de lesões na articulação do joelho. Estudos realizados por Pereira Júnior e Lima (2008), concluíram que o sobrepeso e a obesidade possuem relação significativa para o aparecimento da dor anterior no joelho, ocasionando disfunções musculoesqueléticas e limitação nas atividades de vida diária e prática esportiva.

Foi encontrado sobrepeso em 29\% dos participantes, todavia este achado deve ser levado em consideração à condição da prática de atividade física, podendo este ser um fator de aumento da massa magra, condição esta que favorece a boa função do joelho.

\section{CONCLUSÃO}

Com este estudo, pode-se observar que os praticantes de musculação apresentam uma integridade funcional de seus joelhos, isso se deve a prática adequada e a dose certa do exercício físico, para a musculatura que protege as articulações dos joelhos, permitindo uma boa função músculo-articular, estabilizando esta articulação.

O treinamento de força mostrou-se como um dos métodos mais eficazes para a manutenção da saúde e da força muscular, assim, os benefícios deste se estendem desde como complemento junto ao treinamento de atletas até a reabilitação de diferentes disfunções que comprometam o sistema músculo-esquelético.

Desta maneira conclui-se que a prática da musculação é benéfica para a articulação do joelho, desde que seja executada de maneira correta e supervisionada por profissionais capacitados. 


\section{REFERENCIAS}

BAKER, V. et al. Abnormal knee position sense in individuals with patellofemoral pain syndrome. $J$ Orthop Res, v. 20, p. 208-214, 2002.

DUGAN, S. A. Sports-related knee injuries in female athletes: What gives? Am J Phys Med Rehab, v. 84, n. 2, p. 122-130, 2005.

ELIAS, J. J. et al. Evaluation of a computational model used to predict the patellofemoral contact pressure distribution. J Biomech, v. 37, p. 295-302, 2004.

DELGADO, C. et al. Utilização do esfignomanômetro na avaliação da força dos músculos extensores e flexores da articulação do joelho em militares. Rev Bras Med Esporte, v. 10, n. 5, 2004.

GIL, A. C. Métodos e técnicas de pesquisa social. 4. ed. São Paulo: Atlas, 1994.

MACNICOL, M. F. O joelho com problema. São Paulo: Manole, 2002

McCONNELL, J. Complicações da articulação patelofemoral e considerações pertinentes. In: ELLNBECKER, T. S. Reabilitação dos ligamentos do joelho. São Paulo: Manole, 2002.

MALANKA, G. A.; LEE, W. S. Patellar injury and dislocation. New Jersey. Jan. 2003.

KRAEMER, W. J.; RATAMESS, N. A. Fundamental of resistance training: progression and exercise prescription. Med Sci Sports Exerc, v . 36, n. 1, p. 674-88, 2004.

PEREIRA JÚNIOR, A. A., LIMA, W. C. Avaliação do nível e tipo de atividade física em indivíduos com Síndrome Patelofemoral. Rev Unifebe, n. 5, 2007.

Relação entre a função do joelho e índice de massa corporal na Síndrome Patelofemoral. Ter Man, v. 6, n.26, 2008.

Aplicação da escala de Lysholm em indivíduos com Síndrome Patelofemoral. Rev Fisioter Espec, v. 3, n. 5, 2008.

RAMOS NETO, J. Comparação entre duas escalas para diagnóstico auxiliar de joelho e desempenho em testes funcionais. 2000. (Dissertação) - Universidade do Estado de Santa Catarina, Florianópolis, 2000.

SERVI, J. T. Patellofemoral joint syndromes. Disponível em: http://www.medicine.com/articles. Acesso em: 18 jun. 2003.

SCHUlZ, D. A. Anatomia. In: ELLENBECKER, T. S. Reabilitação dos ligamentos do joelho. São Paulo: Manole, 2002.

TEGNER, Y.; LYSHOLM, J. Rating systems in evaluation of knee ligament injuries. Clin Orthop, v.198, p. 43-49, 1985. 


\section{ALTAIR ARGENTINO PEREIRA JÚNIOR}

UDESC; UNIFEBE; UNIASSELVI

ROSANA FÁTIMA DE ALMEIDA

UNIFEBE

\section{Referencia do artigo}

\section{ABNT}

PEREIRA JR, A, A.; ALMEIDA, R. F. Avaliação funcional do joelho em praticantes de musculação. Conexões, v. 8, n. 2, p. 83-92, 2010.

\section{APA}

Pereira Jr. A, A., \& Almeida, R. F. (2010). Avaliação funcional do joelho em praticantes de musculação. Conexões, 8(2), 83-92.

\section{VANCOUVER}

Pereira Jr. AA, Almeida RF. Avaliação funcional do joelho em praticantes de musculação. Conexões, 2010; 8(2): 83-92.

Recebido em: mar./2010

Aceito para publicação em: jul./2010 